\title{
Is psychology purely a western philosophical concept?
}

\author{
Kripa Sigdel $^{1 *}$, Sujan Shrestha ${ }^{2}$
}

\section{ABSTRACT}

There is a widespread belief and allegation that Psychology is a Western product. This paper examines this allegation looking at its philosophical origin, scientific advancement and contemporary development. The Western perspective on Psychology is contrasted against Eastern perspective. The paper reviewed several literatures on the history and advancement of Psychology. It also reviewed the literatures on indigenous and multicultural psychology. The paper concluded that until 20th century Psychology was exclusively Western product. The recent emphasis on the role of culture in human psychology has given the space for Eastern perspective. We can be hopeful that Psychology will be more inclusive, diverse and global in future.

Keywords: Western philosophy, Eastern philosophy, Westernization of Psychology, Global Psychology

hen Herman Ebbinghaus said 'Psychology has long past but story history' most of it's origins and historical foundation seems to be laid in western philosophy in literatures. The subject matter of Psychology has been here since the beginning of the time although its systematic, standardized, and organized study is a recent phenomenon. It seems improbable to think that Psychology is purely the product of West since the beginning of the time. But whenever we talk of Psychology, it's origin is traced back to the Philosophers like Plato, Aristotle or Socrates. But rarely we find the tenets of Eastern Philosophies such as Taoism, Confucianism, Buddhism, Hinduism etc. in the origin of Psychology. From the syllabus that we follow to the textbook that we refer we as scholars, teachers and students have been primed to think Psychology in terms of Western model.

Transcending the universality of Psychology, culture and context have been recognized as a great influencer to human psyche. This approach says that there is nothing universal and absolute in terms of human psychology. Everything is relative and contextual. This gave birth to cultural psychology, indigenous psychology and cross-cultural Psychology. The influence of this approach is to such an extent that it laid the foundation for the fourth force of multiculturalism (Pederson, 1999). We can say that this new cultural awakening of Psychology has definitely given a space and consideration for local culture and context

\footnotetext{
${ }^{1}$ Lecturer, Padmakanya Multiple Campus, Executive Director, Psychbigyaan Network Nepal- PNN

${ }^{2}$ Lecturer, St. Xavier's College, President, Psychbigyaan Network Nepal-PNN

*Responding Author

Received: January 27, 2021; Revision Received: February 23, 2021; Accepted: March 12, 2021

(C) 2021, Sigdel K. \& Shrestha S.; licensee IJIP. This is an Open Access Research distributed under the terms of the Creative Commons Attribution License (www.creativecommons.org/licenses/by/2.0), which permits unrestricted use, distribution, and reproduction in any Medium, provided the original work is properly cited.
} 
although we can argue that the knowledge production in cultural and indigenous psychology still suffer from Western research paradigm and research methodologies.

The resurgence of Eastern Philosophies into the current model of Psychology can be seen lately but with the tinge of Westernization. The western scientist and scholars have understood the significance and relevance of Eastern philosophies. They have begun to incorporate the concept in their work and research. At the same time while going under the process of adaptation, translation, interpretation and practice they have been morphed into different than the original. The concepts which were borrowed from the East have undergone westernization, particularly Americanization and have been presented to the world including the East in a new platter.

Western Philosophy is known to be credited for the origin of Psychology so this paper will look in depth about the role of Eastern Philosophy as well Western Philosophy in the understanding of Psychology today. Some have also concluded that the field of psychology is no more than a cultural product of the Western world (Rozin,2003) and others encourage integration of the bodies of knowledge and acknowledge of mutual concern of the Western psychology and Eastern philosophies in understanding the thinking, feeling, experiencing and acting (Page \& Berkow, 1991)

Origin of Psychology

\section{Western Philosophy on Psychology}

Aristotle who is contested as a father of Psychology is believed to have had a first book published on Psychology, De Anima - translated as On the Soul published in 350 B..C (Aristotle, 2018). His predecessors Socrates and Plato had also contributed to the field of Psychology with their philosophical ideas. Socrates started the philosophical enquiry about human behaviours- the legacy of which is still continued in the form of Socratic questioning used widely in Therapeutic and Counselling setting. ("Philosophical Roots of Psychology", 2020) His student. Plato continued the tradition of his teacher, Socrates, even more espousing the ideas of Socrates and adding new elements to it. Plato emphasized the role of Psyche or soul which is central to drive our actions, drives, emotions and thinking (Katona, 2002). Plato believed that the soul was distinct from our body and the knowledge would be stored in soul even after our body was dead. His student, Aristotle had a different idea about soul who popularized the experience as epistemology of knowledge. He refuted the idea of Plato that soul and body are separable, He was of the idea that soul and body were united (Katona, 2002). His contribution to the method of study i.e., the empirical approach to study has been largely adopted by the current scientific community as the essential value of science, His idea about soul-body problem which later became mind-body problem was an important philosophical departure from his predecessors and formed the basis for modern Psychologists to study on mind-body dualism.

It is to be noted that the word 'Psychology' is in fact derived from the Greek words 'Psyche' and 'Logos'. The focus on 'soul' as the subject matter of study by Greek Philosophers had contributed the coinage of the term. 'Psyche' is roughly translated as 'soul, breathe, spirit' and 'Logos' is translated as 'Study of or research'. Psychology as we know today is quite different from the meaning Greek Philosophers had attached to it. Generally, when we study the history of Psychology, this is as far as its origin is traced back with nothing or very few words for Eastern Philosophy. 


\section{Eastern Philosophy on Psychology}

East is always considered or viewed as 'mystical' by the westerners. When Psychology is almost exclusively associated with Western Philosophy it begs the question, weren't the people in the East curious about their mind and behaviors? We will look into four major Eastern philosophies i.e., Confucianism, Taoism, Buddhism and Hinduism and derive the meaning they have associated with Psychology.

Confucianism is the philosophy of great Chinese Philosopher Confucius. Confucianism has heavily emphasized on morality and virtues. Human behavior were evaluated on the attainment of five virtues for moral life - humanity, duty to others, sensitivity to other's feeling, wisdom and truthfulness (Mcknight, 2011). The major contribution of Confucianism is on contemporary moral psychology (Kim, 2016). Lao Tzu like Confucius at the same time around developed the philosophy of Taoism, It is the Chinese philosophy that focuses on the harmony with nature and society (Hurley \& Callahan, 2008). The important aspect of this philosophy is that life should be lived in balance or to achieve harmony in life two opposing forces - yin and yang - should be in balance. Hinduism believes in purity of one's soul (aatman) which is determined by one's own actions in current life that is called karma. Karma is the accumulated good and bad deeds of one's present which determines the state of afterlife and reincarnation after death (Chakkarath, 2005). Hinduism treats soul as something that is divine and it gets pure or polluted by an individual's actions or deeds in life. Buddhism basically views life is suffering brought by our endless desires and wishes (Mcknight, 2011). It advocates the following of virtues which includes love, compassion, joy, equanimity to achieve, Nirvana, the state at which life is no more suffering.

Besides these philosophies there are other traditions and philosophies that have influenced the psyche of the people of the Eastern Part of the world. These philosophies have rich cache of psyche to govern one's life that one must wonder why were these philosophies not included in the origin of Psychology? The psychology when it was being made scientific had the available reference material of Western philosophies as the world took notice of Eastern Philosophies quiet later on. The socio-political environment of the world, the advancement of Education, colonization and other external factors could have eclipsed these philosophies. Then there is this Ethnocentric concept, 'White men's burden' which states that the white people have responsibility to educate the rest of the world from their backward state. This imposition of knowledge by the Western World might have obscured the rich philosophical knowledge and wisdom of the East. At the same time, when the science and research was advancing in the west in the field of Psychology, it was quiet nonexistent in the eastern part due to lack of education. This research lag has put the Eastern philosophy into a major disadvantage to push its ideas infront of the world. This could be attributed by the poor culture of research doing, preservation of knowledge and documentation in the Eastern part of the world.

\section{Modern Psychology}

In 1879, at University of Leipzig, Wilhelm Wundt, a German Psychologist established the first laboratory of Psychology. This had a epochal effect in the field of Psychology. This marked the beginning of scientific era in Psychology. Due to his contribution for making Psychology science, Wilhelm Wundt was conferred with the tile of father of modern Psychology (Schultz \& Schultz, 2015). Psychological concepts were operationalized and made measurable with the standardized questionnaires, structured observation, and other available scientific tools. We can tentatively assume that before the advent of the era of 
Modern Psychology, Psychology was more or less philosophical talk or a good subject matter for time pass for the intellectuals and philosophers. But Psychology didn't just become science just like that if the foundations were not led by the Western Philosophers such as Rene Descartes who recognized the importance of function of mental processes and made a systematic enquiry on the relationship between mind and body (Schultz \& Schultz, 2015). Similarly, the British Empiricists John Locke, George Berkely, David Hume, David Hartley, James Mill and John Stuart Mill were crucial to establish Empiricism as the key medium for knowledge generation. Auguste Comte with his theory of Positivism opened the gateway or showed the possibility for the subjects like Psychology to become Science like natural science subjects by focusing only on observable facts and discarding which cannot be observed.

Since Psychology had a late start in the race of science relative to others, it was desperately trying to catch up with them. Psychology established its relevancy in many applied settings especially in the area of clinical setting, educational setting, business and advertising. We can study the modern Psychology into four major forces: Psychodynamic perspective led by Sigmund Freud; Behaviorism and Cognitive perspective led by John Watson, B F Skinner, Ivan Pavlov, Aaron T. Beck and Albert Ellis; Humanistic perspective led by Carl Rogers and Abraham Maslow; and Multicultural perspective popularized by the figures and personalities such as John W Berry, Ype Poortinga, Paul Pederson etc. All these modern perspectives of Psychology are predominantly Western with some benefit of doubt to multicultural perspective as it has its basis in Indigenous and Cross-Cultural Psychology. American Psychological Association (2002) listed the 100 eminent Psychological personalities of $20^{\text {th }}$ Century. In that all the psychologists listed were Western with no one representing the Eastern part of the world. This list alone gives an idea how much Psychology is Western.

It is one thing to say that Eastern Perspective was not given place while discussing the origin of Psychology but it is entirely a different matter and context not to have one Psychologist from the Eastern World in the list of eminent Psychologists of $20^{\text {th }}$ century. This is a complex question to answer and hence multiple factors are responsible for this. Was it a language barrier - as the writings in the lingua franca of the Eastern Psychologists didn't get the attention? Was it the quality of Eastern Psychologists as their qualification and training were not up to the mark? Was it that the proportion of Psychologists in West relative to East was much more? Or was there inherent bias in Psychology which favored Western Psychologists and their researches? Such questions are important to ask as we are in the $21^{\text {st }}$ century and it will be pity if the list does not name any Eastern Psychologists by the end of $21^{\text {st }}$ century. That is highly improbable but the quantity of the names from Eastern side is still doubtful.

We can conclude that the Psychology till $20^{\text {th }}$ century was purely Western with little place and consideration to Eastern perspective or Psychologists. But it's not necessary that the same fate will be repeated in $21^{\text {st }}$ century because we have much hope due to the advent of latest force in Psychology - Multicultural Psychology.

\section{A New Leeway to Eastern Psychology: Multicultural Psychology}

As the world came closer due to increased globalization, people from different cultural backgrounds had an increased contact with each other. It has become impossible to find a village of only one culture now. But this brought a new challenge to understand each other. Before it was easy to understand and explain behaviors of people because most of them 
operated from the similar cultural framework. Now the challenge is that our cultural assumption does not get us far in understanding and explaining the behaviors of people another cultural background. This was majorly seen in the United States of America and Europe as it had huge influx of immigrants from all around the world.

The empirical researches in Psychology are still dominated by the Western World. The findings derived from such researches are widely generalized into the people of different context and setting. The participants from Western countries account for more than $90 \%$ of the participants in psychological studies. The scholars have noticed this biasness in Psychology and have begun to question them (Nielsen, Haun, Kärtner \& Legare, 2017). They have labeled this biasness as Western, educated, industrialized, rich, and democratic (WEIRD) (Henrich, Heine, \&Norenzayan, 2010). The empirical evidences generated mostly from Western sample in Western context and setting with Western theories have made Psychology lopsided more towards Western Philosophy. Western Psychology originally assumed universal traits, behaviors and thinking. The researches mostly done in West were generalized in other parts of the world as well. But the Psychologists noticed that the focus on universality and generalization did not work in other different cultures. The non- Western Psychologists started to become assertive to have their own perspectives and their voices heard. They started to formulate their own theories and explanations relative to their culture which gave rise to Indigenous Psychology.

In both the instances we can see the role of culture is central to human behaviors (Kitayama \& Cohen, 2010). Hence culture became one of the important factors and context for understanding and explaining behavior. It is not enough now to assume that alone findings of a Psychological research are valid across all the cultures. This gave birth to cross cultural psychology which does the psychological study across multiple cultures and see the similarities and differences in the behavior due to culture.

Multicultural Psychology considers Western Psychology culture specific and hence considers an indigenous Psychology native to Western people and culture. This has diversified the field and made it more open and receptive to different views and explanations. The professional agencies such as APA has already acknowledged the importance of cultural knowledge because of which it is mandatory now to have cultural competence that should be reflected in their educational qualification, training, research and Practice (APA, 2002; APA, 2017) to have professional accreditation.

Eastern Psychology is finding more place in the mainstream Psychology due to indigenous and cross- cultural psychologies. For example, in our country Nepal, there has been lots of researches in mental health and its association with culture. The scoping review by Chase., Sapkota, and Kramer (2018) on culture and mental health in Nepal found out the influence of culture on mental health in four different levels :(1) cultural determinants of mental illness; (2) beliefs and values that shape illness experience, including symptom experience and expression and help-seeking; (3) cultural knowledge of mental health and healing practices; and (4) culturally informed mental health research and service design. Such researches give an idea about local Psychology in relation to Psychology of other cultures.

The development of multicultural psychology is definitely positive in making Psychology diverse, inclusive and global. But there are still some issues surrounding researches done in multicultural psychology. First, although there is an increase of authorship by Eastern Psychologists but still the knowledge production of Psychology related to culture is still 
dominated by the Western Psychologists. This is truer for the resource strapped country like ours. The main challenge of this kind of research that is the chance of ethnocentrism. Western researchers come here and do the Psychological researches related to culture which essentially is no problem. But with their preconceived notion, if they interpret the local culture with their cultural lens then that's the huge injustice. This is a real possibility. Another challenge to this is that who gets benefitted the most by such researches? The researchers themselves or the local cultural community also gets benefitted? The other challenge is in the epistemology. Even the indigenous researches done by the local Psychologists might be culturally invalid if the local researchers follow the Western conceptual framework and paradigm of research in the quest to make research more scientific (Hwang, 2004). Indigenous Psychologists advocate to make the research unique to its cultural context, values, concepts, methodologies etc (Kim, 2000). We can be more hopeful for the coming future as more local Psychologists are feeling the need to have their own indigenous Psychologies as many of them have realized that Psychological theories from West do not work in their local setting.

\section{Old Wine in a New Bottle: A Case Analysis of Mindfulness}

As we have already stated above that the world is getting more shrunken into a global village with people from diverse groups and backgrounds. This has given the western world exposure to the eastern philosophies and practices such as tai- chi, yoga and meditation. Western Psychologists and society have been increasingly adopting to Eastern philosophy such as Buddhism and popularizing the practices such as yoga and meditation (Hurley \& Callahan, 2008).

The west has particularly adopted the meditation derived from Buddhist tradition and philosophy. Western Psychology has taken it in its core that it is getting popular day by day. Under Buddhist philosophy and tradition, meditation is a mean to understand the real nature of self which is impermanent and interdependent to eradicate the human sufferings (Dalai Lama, 1986, as cited in Shiah, Hwang, \& Yit, 2017). This Buddhist practise of contemplative meditation was adopted and adapted by Kabat- Zinn, Western scientist ad Mindfulness Based Stress Reduction (MSBR) . MSBR (in short mindfulness meditation) garnered an increased following and now it has been adapted in psychotherapeutic interventions such as Mindfulness based Cognitive Behavioural Therapy (Zinn, 1982). When it wasn't adopted and adapted by West this form of meditation was limited to monks, nuns and few Buddhist followers. The east by and large had not taken notice. Now when the west adopted it and adapted to its purpose with scientific backing it became a huge brand. The popularity of the mindfulness and interest in it is increasing day by day. This is can be seen by the figure below which shows the exponential growth in the quantity of researches in mindfulness from 1980-2018. 
Figure 1Figure showing the exponential growth of publications in mindfulness over the years

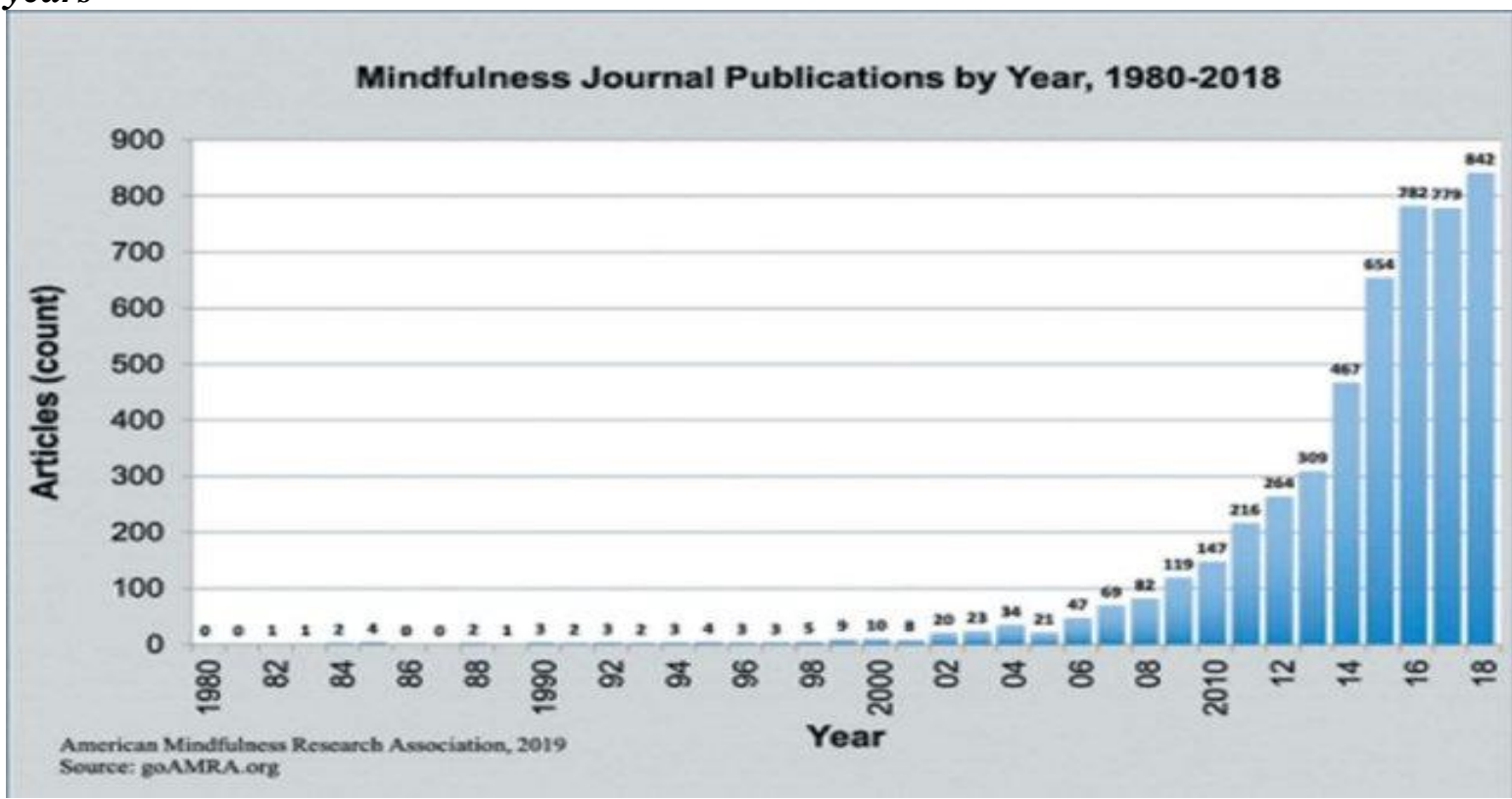

Note: From American Mindfulness Research Association (2019). This image is free for reuse and reprint for research and teaching purposes but modifications to the image are not allowed.

Shiah, Hwang, and Yit (2017) have shown the differences of the original Buddhist tradition of meditation and Mindfulness meditation. The original Buddhist meditation has religious significance attached to it but West has stripped the religiosity out of it and made it secular. Mainly this has been used as a technique to calm down, relax in order to reduce stress levels in the West but original Buddhist meditation is to improve knowledge of oneself to attain Nirvana. Mindfulness meditation in the west has been coupled with therapeutic intervention in order to treat psychological disorders such as depression and anxiety. The Western adaptation of Buddhist meditation as mindfulness has not only impacted the people in West but it is increasingly becoming popular in the East as well.

It is interesting and fascinating to see how the original Eastern concept which was limited to particular cult of people gets taken up by the west. They redress it with practical purpose with scientific backing and offers it back to the place of its origin with new avatar but essentially it is the same. And people in the East accepts it as if it something new and Western.

This only shows how we are poor in understanding the Eastern values and concept and utilise it in our practical lives effectively. It also shows our poverty of research and scientific imagination. It also shows there are so many concepts and practises that need our attention and need scientific investigation. Or else we might become the passive consumers of the Westernization of our own concepts and practices.

\section{DISCUSSION AND CONCLUSION}

The answer to the question which is the main theme of this essay - Is Psychology purely a Western Philosophical Concept has been explored here. In the beginning when there was no distinct discipline of Psychology, both the worlds - East and West had their own philosophies on Psychology. The west was more rational in its approach whereas the East 
was quiet vague and fatalistic. The disparity between East and West began when the West integrated the Science into Psychology. It became exclusively Western till $20^{\text {th }}$ century. But multiculturalism forced Western Psychology to consider other viewpoints and perspectives. Culture became the main force of reckoning in Psychology and is still continuing to be. This opened the avenues for Eastern Psychologists to protest and criticize the universality of Western Psychology and initiate the new fields of Psychology such as Indigenous Psychology and Cross-Cultural Psychology. The Eastern Perspective have begun to find their ways into mainstream Psychology. Despite this positive change there is an issue of ethnocentrism, maximum knowledge generation in one particular place using the biased sample and there is a big question of epistemology of knowledge and methodology. The West is being more open and receptive to Eastern perspectives and practices. The downside of it is that they have westernized our concepts and selling us as a new product, and we are becoming passive observers and consumers of their rebranding of our own original product. To conclude, Psychology is being more diverse, inclusive and global. It is no longer the sole entity of west. But it still is hugely influenced by the Western Philosophy. To make Psychology fully integrated with other perspective takes a time. The local Psychologists should increase their awareness in their own culture and should develop a habit to critically analyze the knowledge production of the West.

\section{REFERENCES}

American Mindfulness Research Association. (2019). Journal articles on mindfulness continue togrow in 2018. Retrieved from https://goamra.org/journal-articles-onmindfulnesscontinue-to-grow-in-2018/

American Psychological Association (2002). Guidelines on Multicultural Education, Training, Research, Practice, and Organizational Change for Psychologists. Retrieved from https://www.apa.org/about/policy/multicultural-guidelines-archived.pdf

American Psychological Association. (2002, July). Eminent psychologists of the 20th century. Monitor on Psychology, 33(7). http://www.apa.org/monitor/julaug02/eminent

American Psychological Association. 2017. Multicultural Guidelines: An Ecological Approach to Context, Identity, and Intersectionality. Retrieved from: http://www.apa.org/about/policy/multicultural-guidelines.pdf

Aristotle. (2018, April). Human Intelligence. http://www.humaniq.org/aristotle.shtml

Chakkarath, P. (2005). What can Western Psychology Learn from Indigenous Psychologies? - Lessons from Hindu Psychology. In W. Friedlmeier, P. Chakkarath, \& B. Schwarz (Eds.), Culture and human development: The importance of cross-cultural research for the social sciences (p. 31-51). Psychology Press/Erlbaum (UK) Taylor \& Francis.

Chase, L. E., Sapkota, R. P., Crafa, D., \& Kirmayer, L. J. (2018). Culture and mental health in Nepal: an interdisciplinary scoping review. Global mental health (Cambridge, England), 5, e36. https://doi.org/10.1017/gmh.2018.27

Henrich, J., Heine, S. J., Norenzayan, A. (2010). The weirdest people in the world? Behavioral \& Brain Sciences, 33, 61-83.

Hurley, E., \& Callahan, J. L. (2008). Integrating eastern philosophy into western psychology: a primer Integrating eastern philosophy into western psychology. Modern Psychological Studies, 13(2). Retrieved from https://scholar.utc.edu/mps/vol13/iss2/5

Hwang, K.-K. (2004). The epistemological goal of indigenous psychology: The perspective of constructive realism. In B. N. Setiadi, A. Supratiknya, W. J. Lonner, \& Y. H. Poortinga (Eds.), Ongoing themes in psychology and culture: Proceedings from the 
16th International Congress of the International Association for Cross-Cultural Psychology. https://scholarworks.gvsu.edu/iaccp_papers/265

Journal of Psychology and Counseling Vol. 1(1) March, 2009 Available online at http://www.academicjournals.org/JPC (C) 2009 Academic Journals

Kabat-Zinn, J. (1982). An outpatient program in behavioral medicine for chronic pain patients based on the practice of mindfulness meditation: Theoretical considerations and preliminary results. General hospital psychiatry, 4(1), 33-47.

Kim, R. (2016). Early Confucianism and Contemporary Moral Psychology. Philosophy Compass, 11(9), 473-485. doi:10.1111/phc3.12341

Kim, U. (2000). Indigenous, cultural, and cross-cultural psychology: A theoretical, conceptual, and epistemological analysis. Asian journal of Social Psychology, 3(3), 265-287

Kitayama, S., \& Cohen, D. (Eds.). (2010). Handbook of cultural psychology. Guilford Press. Mcknight, P. (2011). Eastern and Western Perspectives on Positive Psychology. In C. R. Snyder, S. J. Lopez, \& J. T. Pedrotti (Eds.), Positive psychology: The scientific and practical explorations of human strengths. (pp. 19-51). Thousand Oaks, Calif: SAGE.

Nielsen, M., Haun, D., Kärtner, J., \& Legare, C. (2017). The persistent sampling bias in developmental psychology: A call to action. Journal of Experimental Child Psychology, 162, 31-38. doi: 10.1016/j.jecp.2017.04.017

Page, R.C., \& Berkow, D.N. (1991). Concepts of the self: Western and eastern perspectives. Journal of Multicultural Counseling and Development, 19, 83-93

Pedersen, P. (1999). Multiculturalism as a fourth force. Philadelphia: Brunner, Mazel.

Philosophical Roots of Psychology. (2020). Retrieved 26 September 2020, from https://us.sagepub.com/sites/default/files/upm-assets/108529_book_item_108529.pdf

Rozin, P. (2003). Five potential principles for understanding cultural differences in relation to individual differences. Journal of Research in Personality, 37, 273-283.

Schultz, D. P., \& Schultz, S. E. (2015). A history of modern psychology. Cengage Learning.

Shiah, Y., Hwang, K., \& Yit, K. (2017). Eastern Philosophies and Psychology. [Place of publication not identified]: Frontiers Media SA.

\section{Acknowledgement}

The author appreciates all those who participated in the study and helped to facilitate the research process.

\section{Conflict of Interest}

The author declared no conflict of interest.

How to cite this article: Sigdel K. \& Shrestha S. (2021). Is psychology purely a western philosophical concept? International Journal of Indian Psychology, 9(1), 630-638. DIP:18.01.064/20210901, DOI:10.25215/0901.064 